\title{
Effect of Hot Water Extract from Agaricus Blazei Murill on Chemotaxis of Neutrophils
}

\author{
Mayuko Miyagawa $^{1}$, Yuriko Hirono ${ }^{1}$, Ayaka Kawazoe ${ }^{1}$, Eri Shigeyoshi ${ }^{1}$, Masahito Nose ${ }^{1}$, \\ Masaaki Sakura $^{1}$, K. E. Pinkerton ${ }^{2}$, Minoru Takeuchi ${ }^{1 *}$ \\ ${ }^{1}$ Department of Animal Medical Science, Faculty of Life Sciences, Kyoto Sangyo University, Kyoto, Japan; ${ }^{2}$ Center for Health and \\ the Environment, University of California, Davis, USA. \\ Email: ${ }^{*}$ mtakex@cc.kyoto-su.ac.jp
}

Received October $3^{\text {rd }}, 2012$; revised November $5^{\text {th }}, 2012$; accepted November $14^{\text {th }}, 2012$

\begin{abstract}
Hot water extract from the edible Brazilian mushroom, Agaricus Blazei Murill (ABM), is used for both traditional and alternative medicine. ABM is reported to stimulate anti-tumor, anti-infection, and immune activity. However, there are few reports of how ABM affects neutrophils. Therefore, in this study, we examined the effect of hot water ABM extract on neutrophil migration, phagocytosis, and reactive oxygen species production using neutrophils from guinea pig. Migratory direction and velocity as indicators of chemotactic activity of neutrophils were significantly $(p<0.001)$ increased at concentration of 50 and $100 \mathrm{mg} / \mathrm{ml}$ in ABM extract compared with control. Phagocytic activity of neutrophil was significantly $(\mathrm{p}<0.01)$ increased at concentration of $5 \mathrm{mg} / \mathrm{ml}$ in ABM extract compared with control. Production of reactive oxygen species (ROS: $\mathrm{H}_{2} \mathrm{O}_{2}$ or $\left.\mathrm{O}_{2}^{-}\right)$by neutrophils was significantly $(\mathrm{p}<0.01)$ increased at concentration of $5 \mathrm{mg} / \mathrm{ml}$ in ABM extract compared with control. These results suggest that enhancement in neutrophil chemotactic activity, phagocytic activity and ROS production are mechanisms by which ABM extract inhibits bacterial infection in the skin and dermatitis.
\end{abstract}

Keywords: Neutrophil; Chemotactic Activity; Phagocytic Activity; ROS Production; Agaricus Blazei Murill

\section{Introduction}

Agaricus Blazei Murill, an edible and medicinal mushroom [1], is found in the Piedate region of Sao Paulo, Brazil, where it is popularly known as "Cogumelo do Sol". Agaricus Blazei Murill (ABM) is reported to stimulate anti-tumor, anti-infection, and immune activity [2-4]. The hot water extract of ABM is used particularly in Japan and Brazil as preventive medicine for cancer, hepatitis, atherosclerosis, hypercholesterolemia, dermatitis and allergy $[1,5,6]$.

Although $\mathrm{ABM}$ is believed to stimulate the immune system, there are few reports of how ABM affects neutrophils. In bacterial infection, neutrophils migrate to the site of infection, produce Reactive Oxygen Species (ROS) and phagocytize bacteria. Bernardshaw and colleagues found that ABM inhibits systemic S. pneumonide 6B infection in mice [4], however, the exact mechanism of inhibition remains unclear. Currently, there is no literature describing studies of chemotactic activity of ABM extract for neutrophils. Therefore, in this study, we examine the effect of hot water ABM extract on neutrophil migration, phagocytosis, and Reactive Oxygen Species

${ }^{*}$ Corresponding author.
(ROS) production using neutrophils from guinea pig.

\section{Materials and Methods}

\subsection{Preparation of Agaricus Blazei Murill (ABM) Extract}

Kyowa Wellness Co., Ltd. (Nihonbashi-Hakozaki-cho, Chuo-ku, Tokyo, Japan) provided the Agaricus Blazei Murill (ABM) extract. Briefly, the dried fruiting bodies of ABM were extracted with hot water by the method of Mizuno et al. [7]. Components of ABM (100 g) included water (3.4 g), protein (37.4 g), lipid (3.4 g), fiber (4.7 g), saccharide $(45.0 \mathrm{~g})$ and $\mathrm{Na}(6.0 \mathrm{mg})$. The ABM extract was centrifuged at $1800 \times \mathrm{g}$ for $10 \mathrm{~min}$ to remove any mushroom pieces. The supernatant was freeze dried, diluted to $100 \mathrm{mg} / \mathrm{ml}$ with PBS (-) $\left[\mathrm{Ca}^{2+}, \mathrm{Mg}^{2+}\right.$-free Dulbecco's phosphate buffered saline (Nissui Pharmaceutical, Tokyo, Japan)], sterilized by $0.22 \mu \mathrm{m}$ filtration (Millipore, MA, USA) and stored at $4^{\circ} \mathrm{C}$. Before use, the ABM extract was diluted with PBS (-) to $1 \mathrm{mg} / \mathrm{ml}, 10$ $\mathrm{mg} / \mathrm{ml}$, and $50 \mathrm{mg} / \mathrm{ml}$. Including endotoxin dose in ABM extract was EU/ml. This concentration of LPS didn't response immunologically. Also LPS concentration from to EU/ml didn't show chemotactic activity for neutrophils. 


\subsection{Guinea Pigs}

Male Hartley Guinea pigs were obtained from Japan SLC (Shizuoka, Japan). They were housed in transparent plastic cages with stainless wire lids in the animal facility of Kyoto Sangyo University (Kyoto, Japan). They were maintained under standard conditions, with a dark period from $8 \mathrm{pm}$ to $8 \mathrm{am}$, and water and food were provided $a d$ libitum. This study was approved by the committee for animal care at Kyoto Sangyo University.

\subsection{Isolation of Neutrophils}

Blood was collected from guinea pigs, diluted and mixed twice with PBS (-). An equivalent amount of saline containing 3.5\% dextran was added, and the mixture sat at room temperature for $30 \mathrm{~min}$ to precipitate red blood cells. The leukocyte-rich supernatant was centrifuged at $400 \times \mathrm{g}$ for $30 \mathrm{~min}$ (Ficoll-paque Plus, GE Healthcare, Tokyo, Japan). The precipitation was hemolyzed with lysis buffer and centrifuged at $185 \times \mathrm{g}$ for $5 \mathrm{~min}$. After the supernatant was discarded, Neutrophils were washed twice with PBS (-). Isolated neutrophils were resuspended in RPMI 1640 containing $0.1 \%$ delipidated bovine serum albumin, $100 \mathrm{U} / \mathrm{ml}$ penicillin and $100 \mu \mathrm{g} / \mathrm{ml}$ streptomycin with HEPES or R (+) (RPMI1640 containing $10 \%$ fetal calf serum, $100 \mathrm{U} / \mathrm{ml}$ penicillin and $100 \mu \mathrm{g} / \mathrm{ml}$ streptomycin) at a concentration of $2 \times 10^{6} \mathrm{cel} / \mathrm{ml}$. The percentage of neutrophils was over than $95 \%$ pure.

\subsection{Chemotaxis Assay for Neutrophils}

Chemotactic activity for neutrophils was evaluated with EZ-TAXIScan (GE Healthcare). EZ-TAXIScan was used to detect real time horizontal chemotactic activity of neutrophil. Time-lapse images of neutrophils during migration were obtained using EZ-TAXIScan equipped with a six channel chamber. The chamber has an etched silicon substrate and a flat glass plate, both of which form two compartments with a $4 \mu \mathrm{m}$-deep microchannel. Neutrophils $\left(0.75 \mu \mathrm{l}\right.$ of $2 \times 10^{6}$ cells/ml adjusted with RPMI1640 containing $0.1 \%$ delipidated bovine serum albumin, 100 $\mathrm{U} / \mathrm{ml}$ penicillin and $100 \mu \mathrm{g} / \mathrm{ml}$ streptomycin with HEPES) were put into a hole where the device is held together with a stainless holder, and $0.75 \mu 1$ of PBS (-) as control, $1,10,50$ and $100 \mathrm{mg} / \mathrm{ml}$ of $\mathrm{ABM}$ extract; and $10^{-6} \mathrm{M}$ $\mathrm{N}$-formyl-methionyl-leucyl-phenylalanine (f-MLP) as active control of chemotaxis were added into a contra-hole. The holder assembly was filled with the RPMI1640 solution mentioned above and incubated for $30 \mathrm{~min}$ at $37^{\circ} \mathrm{C}$. A charge-coupled device (CCD) camera was used to record the migration of neutrophils toward the high concentration of each sample. Migrated neutronphils were analyzed by TAXIScan Analyzer2. The radian (rad) and velocity $(\mu \mathrm{m} / \mathrm{sec})$ of migrated neutrophils were calculated by TAXIScan Analyzer2 and used as an indicator of chemotactic activity of neutrophols.

\subsection{Phagocytic Activity of Neutrophils}

Neutrophils $\left(1 \times 10^{6} / \mathrm{ml}\right)$ adjusted with R $(+)$ were incubated at $37^{\circ} \mathrm{C}$ for 20 min with $\mathrm{ABM}$ extract (final concentration $5 \mathrm{mg} / \mathrm{ml}$ ) or PBS (-) (control) and FITC-labeled latex beads (Polyscinences Inc., PA, USA). Neutrophils were washed twice with PBS (-) containing 3 mM EDTA and resuspended in $300 \mu$ of PBS $(+)$ [(PBS $(-)$ containing $1 \%$ fetal calf serum (FCS)]. Phagocytic activity of neutrophils toward the latex beads was measured using a fluorescence activated cell sorter (FACS) Calibur (Becton-Dickinson, CA, USA).

\subsection{Production of Reactive Oxygen Species (ROS) by Neutrophils}

Neutrophils were incubated with 2', 7'-dichlorofluorescin diacetate (DCFH-DA, [Molecular Probes, Eugene, OR, USA], final concentration $2 \mu \mathrm{M}$ ) or hydroethidine (HE, [Polysciences, PA, USA], final concentration $5 \mu \mathrm{M}$ ) at $37^{\circ} \mathrm{C}$ for $15 \mathrm{~min}$. ABM extract was added to achieve a final concentration $5 \mathrm{mg} / \mathrm{ml}$. The control consisted of the addition of an equivalent final concentration of PBS (-). After a shaking incubation for $20 \mathrm{~min}$ at $37^{\circ} \mathrm{C}$, neutrophils were washed twice with PBS $(+)$ and resuspended in PBS $(+)$. Fluorescent intracellular dichlorofluorescein (DCF) and ethidium, indicators of intracellular hydrogen peroxide and superoxide, respectively, were assayed by FACS.

\subsection{Statistical Analysis}

All values are expressed as mean \pm standard deviation (S.D.). Comparisons between control and ABM extract were made with the student's t-test. p-values less than 0.05 were considered statistically significant.

\section{Results}

\subsection{Neutrophils Are Chemotatically Attracted to AMB Extract}

Neutrophils were chemotatically attracted to AMB extract (Figure 1), and the course of migration was similar to the straight pathway taken by neutrophils exposed to f-MLP, a positive control of chemotaxis (Figure 2). Chemotactic activity toward AMB extract was indicated by increased direction and velocity of migrating neutronphils compared to control (Figure 3). Along with neutrophils exposed to f-MLP, neutrophils exposed to 1, 10, 50 , and $100 \mathrm{mg} / \mathrm{ml} \mathrm{ABM}$ extract had significantly greater migratory direction and velocity than the control (except for the direction at $1 \mathrm{mg} / \mathrm{ml}$ of AMB extract).

\subsection{ABM Extract Stimulates Neutrophil Phagocytic Activity}

Neutrophils demonstrated phagocytic activity when exposed to ABM extract at final concentration of $5 \mathrm{mg} / \mathrm{ml}$ 

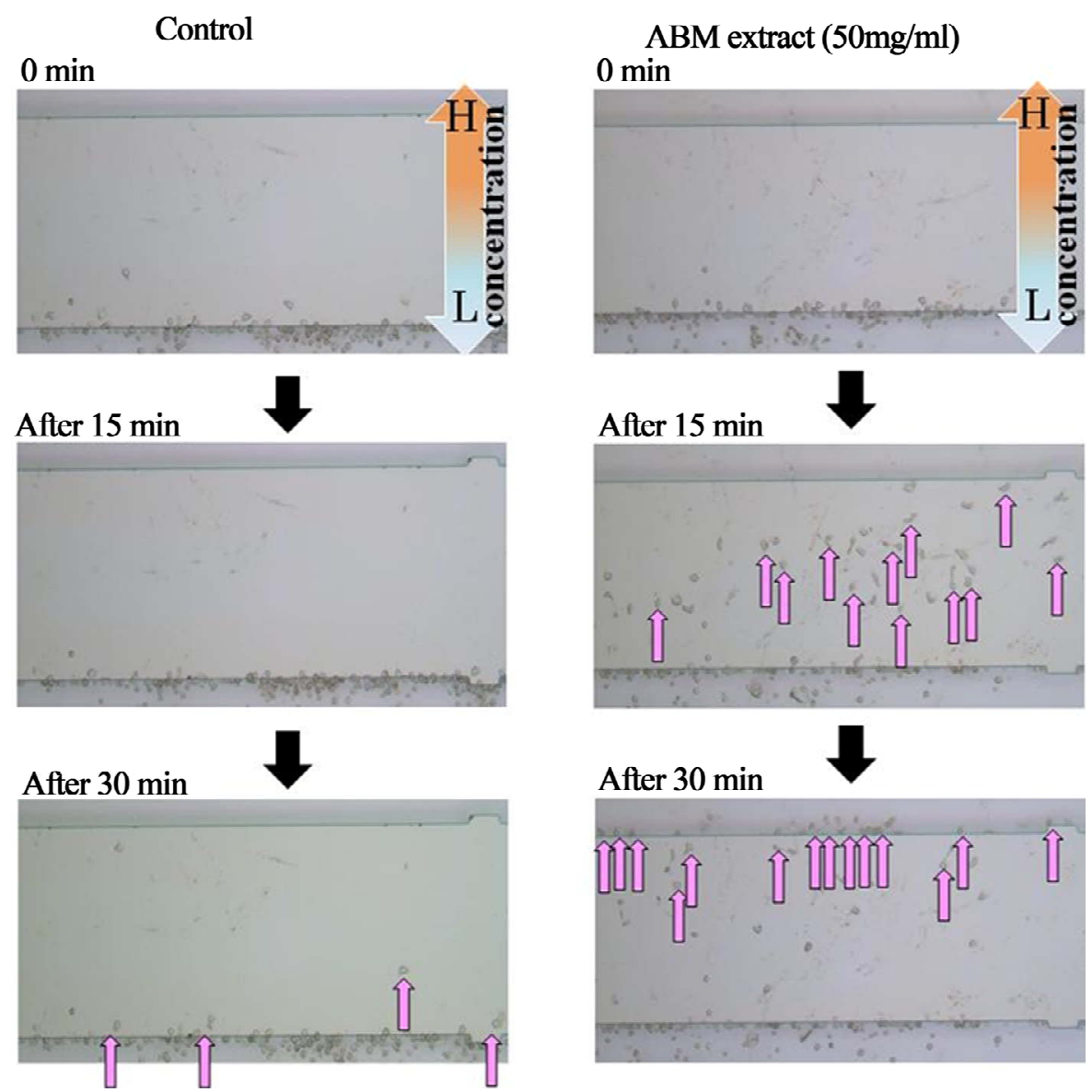

(a)

(b)

Figure 1. Time course and number of migrated neutrophils by ABM extract Chemotaxis assay for neutrophils exposed to PBS (-) or $50 \mathrm{mg} / \mathrm{ml}$ AMB extract. After $15 \mathrm{~min}$, over thirty neutrophils exposed to ABM extract migrated to the middle of the chamber, and after $30 \mathrm{~min}$, over twenty neutrophils migrated to the end of the chamber. Very few neutrophils migrated in response to PBS (-). H: High concentration of ABM extract. L: Low concentration of ABM extract. 11 : Migrated neutrophil.

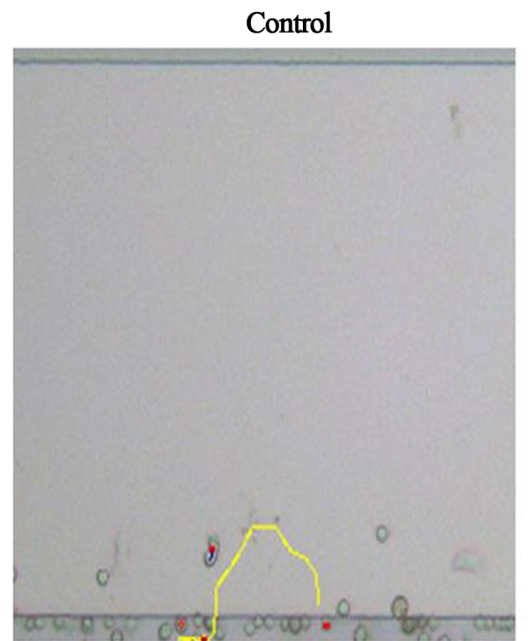

(a)

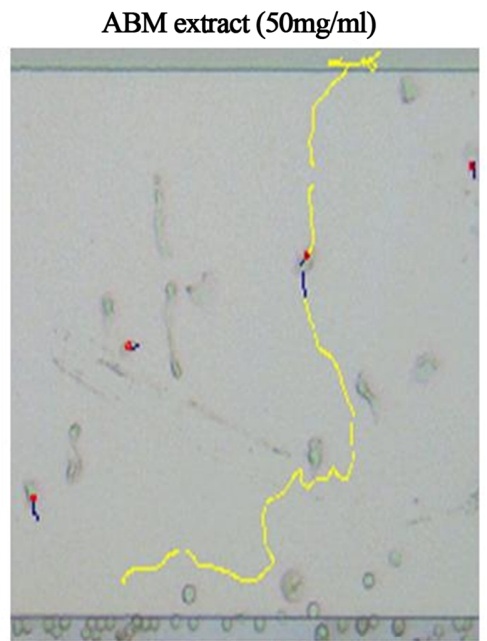

(b)

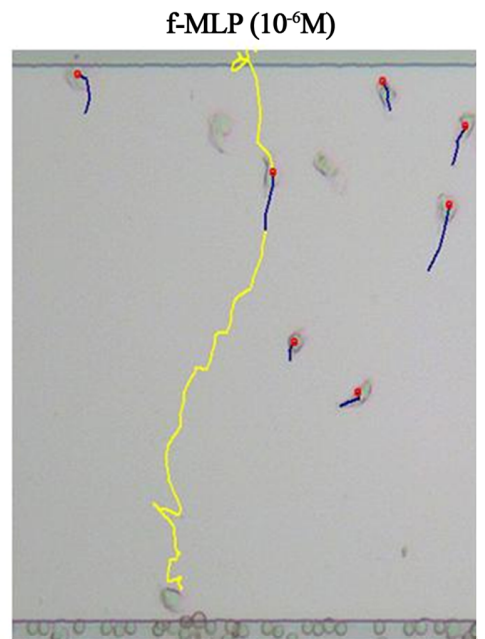

(c)

Figure 2. The pathway of migration in neutrophils by ABM extract. The pathway of migration by neutrophils exposed to PBS $(-), 50 \mathrm{mg} / \mathrm{ml}$ AMB extract, or $10^{-6} \mathrm{M}$ N-formyl-methionyl-leucyl-phenylalanine (f-MLP), which is a positive control for chemotaxis. Yellow lines show migration pathway of neutrophils. 


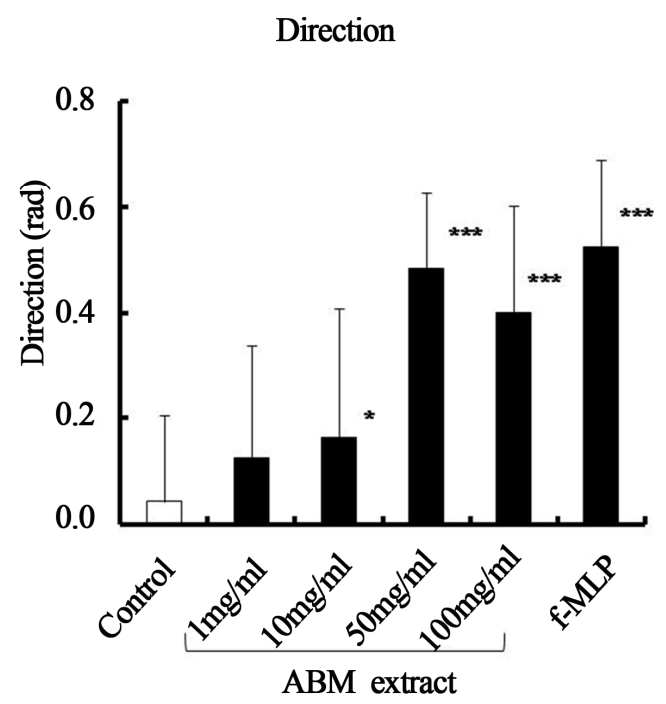

(a)

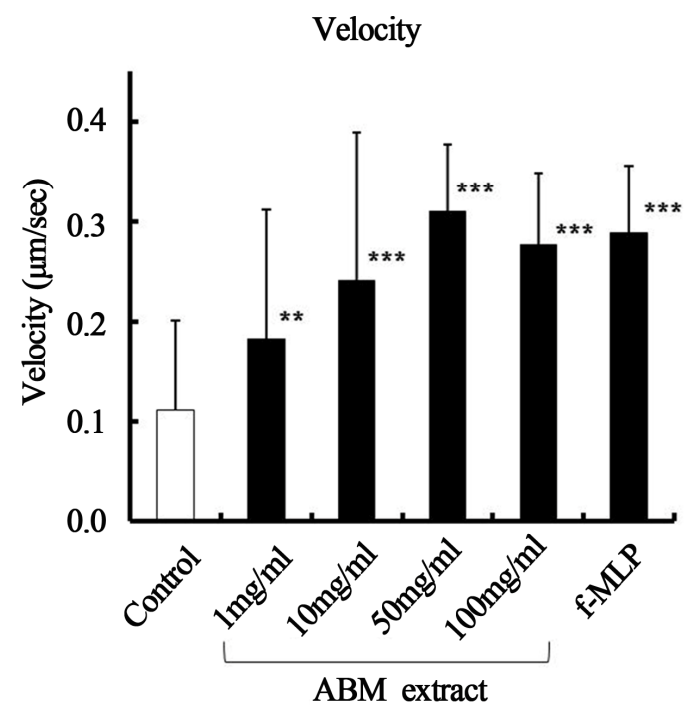

(b)

Figure 3. Effect of ABM extract on the direction and velocity of chemotactic activity for neutrophils. Control: PBS $(-)$. $10^{-6} \mathrm{M}$ N-formyl-methionyl-leucyl-phenylalanine (f-MLP): a positive control of chemotactic activity for neutrophils. $*$ : $\mathbf{p}<0.05, * *$ : $\mathbf{p}<\mathbf{0 . 0 1}$ and $* * *: \mathbf{p}<\mathbf{0 . 0 0 1}$, statistical significance compared with control. The values are shown as mean \pm S.D.

(Figure 4). Compared to the control, neutrophils exposed to ABM extract had 2.4 times more phagocytic activity, a statistically significant increase.

\subsection{ABM Extract Increases Production of Reactive Oxygen Species (ROS) by Neutrophils}

Production of Reactive Oxygen Species (ROS), $\mathrm{H}_{2} \mathrm{O}_{2}$ and $\mathrm{O}_{2}^{-}$, was significantly increased when neutrophils were exposed to ABM extract at final concentration of $5 \mathrm{mg} / \mathrm{ml}$ (Figure 5) compared to control. Production of $\mathrm{H}_{2} \mathrm{O}_{2}$ was 1.5 times greater (Figure 5(a)) and production of $\mathrm{O}_{2}^{-}$ was 2.4 greater (Figure 5(b)) by neutrophils exposed to ABM extract compared with control.

\section{Discussion}

Hot water extract from the edible Brazilian mushroom, Agaricus Blazei Murill (ABM) belonging to the Basidiomycetes family, is used for both traditional and alternative medicine. ABM extract is known for its anti-tumor activity [2,7-11] and ability to activate immune cells, such as $\mathrm{T}$ cells, macrophages and NK cells $[5,12,13]$. A few studies describe ABM extract inhibiting bacterial infection $[4,14]$. Despite the reported anti-bacterial property of ABM hot water extract, there are no reports concerning its chemotactic activity for neutrophils. Therefore, we investigated the chemotactic, phagocytic, and Reactive Oxygen Species (ROS) producing activities of neutrophils when exposed to ABM extract.

We found that neutrophils had increased migrational direction and velocity in the presence of $\mathrm{ABM}$ extract compared with the control (PBS). It has been reported that ABM induces chemokine production, such as IL-8 or CXCL, by macrophages or monocytes $[15,16]$. During bacterial infection, neutrophils migrate toward the pathogen, with major chemotactic factors including $\mathrm{C} 5 \mathrm{a}$, leukotriene $\mathrm{B}_{4}$, Platelet-activating factor (PAF), and chemokines of the CXCL family [17]. In this study, we show that $\mathrm{ABM}$ extract possesses direct chemotactic activity for neutrophils. In effective components, ABM extract is also known to contain $\beta$-glucan, proteoglycan, and ergosterol [18], which are potent stimulators of macrophages, PMNs and NK cells [19-21].

Because a primary function of neutrophils is phagocytosis, we investigated the effect of ABM extract on phagocytic activity of neutrophils using FITC-labeled latex beads. We found that phagocytic activity was significantly increased by ABM extract. Our results correspond with reports of neutrophils from Balb/cByJ mice having increased phagocytic capability when exposed to ABM [22].

The generation of microbicidal oxidants by neutrophils results from the activation of a multi-protein enzyme complex known as the NADP oxidase, which is responsible for transferring electrons from NADP to $\mathrm{O}_{2}$, resulting in the formation of a superoxide anion $\left(\mathrm{O}_{2}^{-}\right)[23,24]$. $\mathrm{O}_{2}^{-}$is rapidly converted to a secondary toxic oxygen species, which can efficiently kill microorganisms. Thus, producing Reactive Oxygen Species (ROS) is a primary host defense mechanism of neutrophils against bacterial infection [25]. We evaluated ROS production of neutrophils using DCFH-DA and HE by FACS [26] and found that $\mathrm{H}_{2} \mathrm{O}_{2}$ and $\mathrm{O}_{2}^{-}$production were significantly in- 


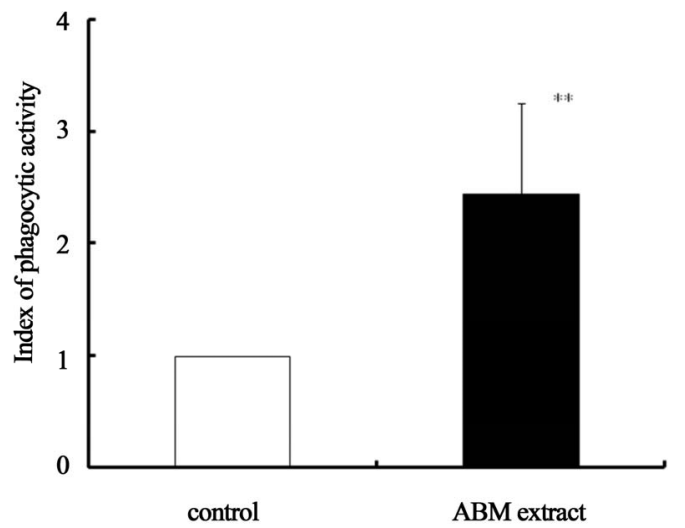

Figure 4. Effect of ABM extract on phagocytic activity of neutrophils. Phagocytic index of the control is 1.0. **: $p<$ 0.01, statistical significance compared with control. The values are shown as mean \pm S.D.

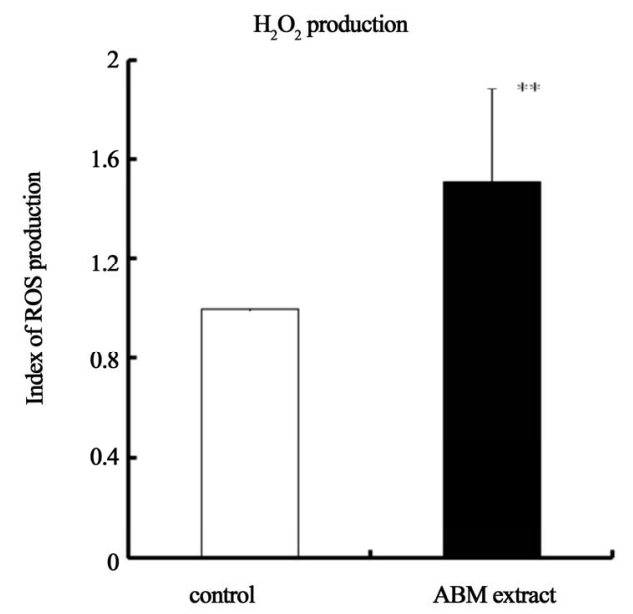

(a)

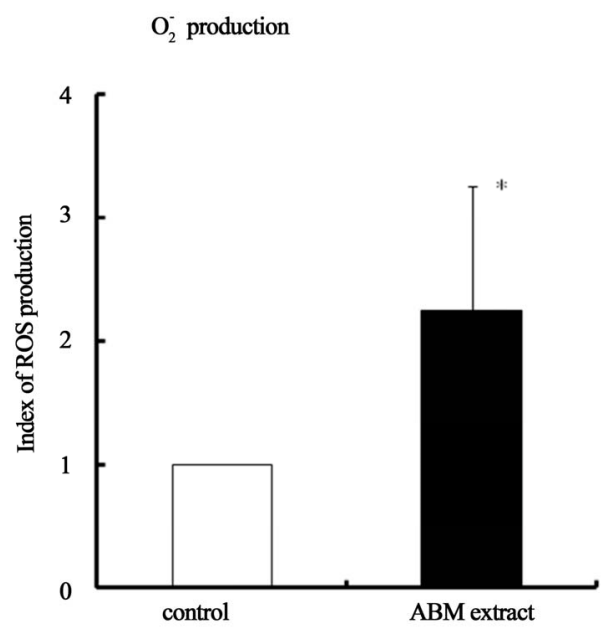

(b)

Figure 5. Effect of ABM extract on reactive oxygen species (ROS) production by neutrophils. ROS production index of control iss 1.0. $*$ : $p<0.05$ and $* *: p<0.01$, statistical significance compared with control. The values are shown as mean \pm S.D. creased by exposure to ABM extract compared with control. These results are similar to a report that ROS production in granulocytes of human whole blood was increased by ABM [27].

In conclusion, this study shows that neutrophil migration, phagocytosis and ROS production are significantly increased by $\mathrm{ABM}$ extract. These results suggest concrete mechanisms by which hot water ABM extract may inhibit bacterial infection in the skin. In future, there is also a possibility for use as cosmetics of skin care by ABM extract is added in cosmetics for protection of bacterial infection.

\section{Acknowledgements}

We appreciate Dr. Suzette Smiley-Jewell for her efforts to provide technical assistance and suggestions in the preparation of this manuscript.

\section{REFERENCES}

[1] S. P. Wasser and A. L. Weis, "Therapeutic Effects of Substances Occurring in Higher Basidiomycetes Mushrooms: A Modern Perspective," Critical Reviews in Immunology, Vol. 19, No. 1, 1999, pp. 65-96.

[2] M. L. Gonzaga, D. P. Bezerra, A. P. Alves, et al., "In Vivo Growth-Inhibition of Sarcoma 180 by an Alpha- $(1 \rightarrow 4)$ glucan-beta- $(1 \rightarrow 6)$-glucan-protein Complex Polysaccharide Obtained from Agaricus Blazei Murill," Journal of Natural Medicines, Vol. 63, No. 1, 2009, pp. 32-40. doi:10.1007/s11418-008-0286-4

[3] R. Kaneno, L. M. Fontanari, S. A. Santos, et al., "Effects of Extracts from Brazilian Sun-Mushroom (Agaricus Blazei) on the NK Activity and Lymphoproliferative Responsiveness of Ehrlich Tumor-Bearing Mice," Food and Chemical Toxicology an International Journal Published for the British Industrial Biological Research Association, Vol. 42, No. 6, 2004, pp. 909-916. doi:10.1016/j.fct.2004.01.014

[4] S. Bernardshaw, E. Johnson and G. Hetland, "An Extract of the Mushroom Agaricus Blazei Murill Administered Orally Protects against Systemic Streptococcus Pneumoniae Infection in Mice," Scandinavian Journal of Immunology, Vol. 62, No. 4, 2005, pp. 393-398. doi:10.1111/j.1365-3083.2005.01667.x

[5] S. P. Wasser, "Medicinal Mushrooms as a Source of Antitumor and Immunomodulating Polysaccharides," Applied Microbiology and Biotechnology, Vol. 60, No. 3, 2002, pp. 258-274. doi:10.1007/s00253-002-1076-7

[6] L. K. Ellertsen and G. Hetland, "An Extract of the Medicinal Mushroom Agaricus Blazei Murill Can Protect against Allergy," Clinical and Molecular Allergy, Vol. 7, No. 1, 2009, p. 6. doi:10.1186/1476-7961-7-6

[7] T. Takaku, H. Kimura and Y. Okuda, "Isolation of an Antitumor Compound from Agaricus Blazei Murill and Its Mechanism of Action," The Journal of Nutrition, Vol. 131, No. 5, 2001, pp. 1409-1413.

[8] H. Kawagishi, R. Inagaki, T. Kanao, et al., "Fractionation 
and Antitumor Activity of the Water-Insoluble Residue of Agaricus Blazei Fruiting Bodies," Carbohydrate Research, Vol. 186, No. 2, 1989, pp. 267-273. doi:10.1016/0008-6215(89)84040-6

[9] H. Kobayashi, R. Yoshida, Y. Kanada, et al., "Suppressing Effects of Daily Oral Supplementation of Beta-Glucan extracted from Agaricus Blazei Murill on Spontaneous and Peritoneal Disseminated Metastasis in Mouse Model," Journal of Cancer Research and Clinical Oncology, Vol. 131, No. 8, 2005, pp. 527-538. doi:10.1007/s00432-005-0672-1

[10] Y. Fujimiya, Y. Suzuki, K. Oshiman, et al., "Selective Tumoricidal Effect of Soluble Proteoglucan Extracted from the Basidiomycete, Agaricus Blazei Murill, Mediated via Natural Killer Cell Activation and Apoptosis," Cancer Immunology Immunotherapy, Vol. 46, No. 3, 1998, pp. 147-159. doi:10.1007/s002620050473

[11] H. Kawagishi, T. Inagaki, T. Kanao, et al., "Fractionation and Antitumor Activity of the Water-In-Soluble Residue of Agaricus Blazei Fruiting Bodies," Carbohydrate Research, Vol. 186, No. 2, 1989, pp. 267-273. doi:10.1016/0008-6215(89)84040-6

[12] E. Yuminamochi, T. Koike, K. Takeda, et al., "Interleukin12- and Interferon-Gamma-Mediated Natural Killer Cell Activation by Agaricus Blazei Murill," Immunology, Vol. 121, No. 2, 2007, pp. 197-206. doi:10.1111/j.1365-2567.2006.02558.x

[13] A. Nakajima, T. Ishida, M. Koga, et al., "Effect of Hot Water Agaricus Blazei Murill on Antibody Producing Cells in Mice," International Immunopharmacology, Vol. 2, No. 8, 2002, pp. 1205-1211. doi:10.1016/S1567-5769(02)00056-5

[14] S. Bernardshaw, G. Hetland, B. Grinde, et al., "An Extract of the Mushroom Agaricus Blazei Murill Protects against Lethal Septicemia in a Mouse Model of Fecal Peritonitis," Shock Augusta Ga, Vol. 25, No. 4, 2006, pp. 420-425. doi:10.1097/01.shk.0000209526.58614.92

[15] L. K. Ellertsen, G. Hetland, E. Johnson, et al., "Effect of a Medicinal Extract from Agaricus Blazei Murill on Gene Expression in a Human Monocyte Cell Line as Examined by Microarrays and Immuno Assays," International Immunopharmacology, Vol. 6, No. 2, 2006, pp. 133-143. doi:10.1016/j.intimp.2005.07.007

[16] K. Sorimachi, K. Akimoto, Y. Ikehara, et al., "Secretion of TNF-Alpha, IL-8 and Nitric Oxide by Macrophages Activated with Agaricus Blazei Murill Fractions in $\mathrm{Vi}$ tro," Cell Structure and Function, Vol. 26, No. 2, 2001, pp. 103-108. doi: $10.1247 /$ csf.26.103

[17] F. Shibata, "The Role of Rat Cytokine-Induced Neutrophil Chemoattractants in Inflammation," Yakugaku Zasshi
Journal of the Pharmaceutical Society of Japan, Vol. 122, No. 4, 2002, pp. 263-268. doi:10.1248/yakushi.122.263

[18] T. Mizuno and M. Kawai, "Chemistry and Biochemistry of Mushrooms," Gakkai Shuppan Center, 1992, pp. 223228.

[19] G. Y. Kim, M. Y. Lee, H. J. Lee, et al., "Effect of Water-Soluble Proteoglycan Isolated from Agaricus Blazei on the Maturation of Murine Bone Marrow-Derived Dendritic Cells," International Immunopharmacology, Vol. 5, No. 10, 2005, pp. 1523-1532.

doi:10.1016/j.intimp.2005.02.018

[20] T. Ebina, "Activation of Antitumor Immunity by Intratumoral Injection of Biological Preparations," Gan to $\mathrm{Ka}$ gaku Ryoho Cancer Chemotherapy, Vol. 32, No. 11, 2005, pp. 1654-1656.

[21] J. P. Angeli, L. R. Ribeiro, M. L. Gonzaga, et al., "Protective Effects of $\beta$-Glucan Extracted from Agaricus Brasiliensis against Chemically Induced DNA Damage in Human Lymphocytes," Cell Biology and Toxicology, Vol. 22, No. 4, 2006, pp. 285-291. doi:10.1007/s10565-006-0087-Z

[22] Y. Chan, T. Chang, C. H. Chan, et al., "Immunomodulatory Effects of Agaricus Blazei Murill in Balb/cByJ Mice," Journal of Microbiology Immunology and Infection, Vol. 40, No. 3, 2007, pp. 201-208.

[23] B. M. Babior, "NADPH Oxidase," Current Opinion in Immunology, Vol. 16, No. 1, 2004, pp. 42-47. doi:10.1016/j.coi.2003.12.001

[24] R. A. Clark, "Activation of the Neutrophil Respiratory Burst Oxidase," The Journal of Infectious Diseases, Vol. 179, 1999, pp. S309-S317. doi:10.1086/513849

[25] R. A. Miller and B. A. Britigan, "The Formation and Biologic Significance of Phagocyte-Derived Oxidants," Journal of Investigative Medicine, Vol. 43, No. 1, 1995, pp. 39-49.

[26] S. Matsugo, M. Sasai, H. Shinmori, et al., "Generation of a Novel Fluorescent Product, Monochlorofluorescein from Dichlorofluorescin by Photo-Irradiationdagger," Free Radical Research, Vol. 40, No. 9, 2006, pp. 959-965. doi:10.1080/10715760600827012

[27] S. Bernardshaw, T. Lyberg, G. Hetland, et al., "Effect of an Extract of the Mushroom Agaricus Blazei Murill on Expression of Adhesion Molecules and Production of Reactive Oxygen Species in Monocytes and Granulocytes in Human Whole Blood ex Vivo," Acta Pathologica, Microbiologica et Immunologica Scandinavica, Vol. 115, No. 6, 2007, pp. 719-725. doi:10.1111/j.1600-0463.2007.apm 619.x 